\title{
Factors Associated with the Infection by Plasmodium vivax in Children and Adolescents from the Brazilian Amazon Basin
}

\author{
Rosa Maria Dias ${ }^{1}$, Larissa Rodrigues da Costa ${ }^{1}$, Agostilina Renata dos Santos da Cruz Ramos ${ }^{1}$, \\ Andrea Graças Ferreira Frazão1, Cláudia Daniele Tavares Dutra1, Fernanda Maria Lima Moura1, \\ Isameriliam Rosaulem Pereira da Silva ${ }^{1}$, José Luiz Fernandes Vieira² \\ ${ }^{1}$ Faculty of Nutrition, Institute of Health Sciences, Para Federal University, Belem, Brazil \\ ${ }^{2}$ Pharmacy Faculty, Campus Universitario do Guama, Para Federal University, Belem, Brazil \\ Email: rosadiasbr@gmail.com, larissadbr@gmail.com,renata9689@hotmail.com,deabrelaz@gmail.com,cdanibr@hotmail.com, \\ fmoura2020@hotmail.com,rosaulen@gmail.com, jvieira@ufpa.br
}

How to cite this paper: Dias, R.M., da Costa, L.R., dos Santos da Cruz Ramos, A.R., Frazão, A.G.F., Dutra, C.D.T., Moura, F.M.L., da Silva, I.R.P. and Vieira, J.L.F. (2020) Factors Associated with the Infection by Plasmodium vivax in Children and Adolescents from the Brazilian Amazon Basin. Advances in Infectious Diseases, 10, 140-147.

https://doi.org/10.4236/aid.2020.102011

Received: April 16, 2020

Accepted: June 14, 2020

Published: June 17, 2020

Copyright $\odot 2020$ by author(s) and Scientific Research Publishing Inc. This work is licensed under the Creative Commons Attribution International License (CC BY 4.0).

http://creativecommons.org/licenses/by/4.0/

(c) (i) Open Access

\begin{abstract}
Objective: To investigate the factors associated with malaria vivax infection in children and adolescents from an endemic area in the Eastern portion of the Brazilian Amazon basin. Methods: A case-control study was carried out in the municipality of Anajas, Brazil, from January 2016 to September 2017. Questionnaires were applied to the relative or the legal tutors of children and adolescents with questions regarding social and economic status, educational degree, knowledge about malaria, and the use of protective measures against mosquito bites. Anthropometric measures were performed in children and adolescents. Results: A total of 58 cases and 61 controls were included in the study. Most of the participants were male, eutrophics, and their relatives presented low educational degrees as well as low social and economic status. The knowledge of malaria was limited, but the percentage of individuals using long-lasting insecticidal nets was high. The presence of peri-domiciliary breeding sites for Anopheles vector was the most critical factor for malaria. Conclusion: The occurrence of malaria was associated with low social and economic status, a low educational degree, the unfamiliarity with malaria and the presence of breeding sites for Anopheles mosquito surrounding individual domiciles.
\end{abstract}

\section{Keywords}

Infectious Diseases, Malaria, Epidemiology, Risk Factor 


\section{Introduction}

Malaria by Plasmodium vivax remains a significant public health issue worldwide, with three billion of individuals who are at risk to contract the disease, and approximately 435,000 each year, the majority in children (61\%) who are a group at risk to develop severe disease [1].

In Brazil, most of the cases (99\%) occur in the Brazilian Amazon basin, which presents a non-homogenous transmission among municipalities, and $P$. vivax accounts for $85 \%$ of cases. Despite the effort of the Brazilian Health Authorities to control the disease, the incidence is still high, with 193,838 cases notified in 2018, amongst them, 45,835 (23.6\%) in the State of Pará [2].

The adequate management of risk factors for malaria, such as the use of longlasting insecticidal nets (LLIN), indoor residual spray (IRS), use of repellent, availability of mosquito breeding sites in the peridomicile and the outdoors activities overnight, contribute for reducing the burden of the disease [3] [4]. In a large endemic area with several geographical, social, and economic scenarios such as the Brazilian Amazon basin, the factors associated with malaria differ among municipalities. Moreover, they are poorly understood in children and adolescents. Therefore, the present study aims to investigate the factors associated with malaria vivax infection in children and adolescents from an endemic area in the Eastern portion of the Brazilian Amazon basin.

\section{Material and Methods}

\subsection{Study Site and Participants}

An epidemiological study of case and control was carried out from January 2016 to September 2017 with children and adolescents from Anajás in the State of Para. The municipality has an average temperature of $23.4^{\circ} \mathrm{C}-26.5^{\circ} \mathrm{C}$, with annual precipitation of 1437.0 - $3022.7 \mathrm{~mm}$ and an annual daylight duration of 1573.5 2443.4 hours. Anajas is located in the Marajo Island $\left(00^{\circ} 59^{\prime} 21^{\prime \prime S}\right.$ and $\left.49^{\circ} 56^{\prime} 24^{\prime \prime} \mathrm{W}\right)$ with 28,012 inhabitants, amongst them, 7337 children aged 20 - 10 years old. The municipality accounts for $10.4 \%$ of cases of malaria in the State of Para.

The participants were included in the study according to the following criteria:

Case children and adolescents aged 2 - 14 years, both genders, with mono-infection by $P$. vivax diagnosed by microscopic examination of Giemsa-stained thick blood films, which were admitted in the study by spontaneous demand after their relatives or legal tutors have searched for the ambulatory of diagnosis and treatment of malaria of the municipality with signs and symptoms suggestive of malaria.

Control: children and adolescents aged 2 - 14 years with a negative microscopic examination of a blood smear on three consecutive occasions as well as with no recent ( 2 years) history of malaria recruited in two public schools of the municipality. The relative or the legal tutors of children or adolescents agreed with the participation in the study and signed the informed consent.

The criteria for the exclusion of the cases from the study were those with signs and symptoms of severe malaria (parasitemia over 5\%, jaundice, pulmo- 
nary or renal impairment, severe anemia, altered levels of consciousness) and self-referred glucose-6-phosphate dehydrogenase (G6PD) deficiency. Case and control with known underlying severe diseases, including congenital diseases, also were excluded.

\subsection{Data Collection}

Data were collected during an interview with the parents or legal tutors of the children and adolescents at their inclusion in the study. The questionnaire applied contained questions regarding social and economic status, educational degree, knowledge about malaria, and the use of protective measures against mosquito bites. The questionnaire was previously validated in a pilot study before the commencement of the study.

The following data were collected from the parents or legal tutor: 1) socioeconomic status: scholar degree (years of study), marital status (stable or unstable), occupation (stable or unstable), family income (below or above 100 US\$).

2) knowledge about malaria: the forms of transmission of the disease, and the use of protective measures against mosquito bites, as the use of long-lasting insecticidal nets (LLIN), indoor residual spray (IRS) and the use of repellent. 3) the presence of peri-domiciliary breeding sites for Anopheles vector.

The following data were collected from the children and adolescents included in this study: weight (kilograms), height (centimeters), age (years), and gender.

\subsection{Anthropometric Measures}

Children and adolescents were weighed with a calibrated digital weight scale $(180 \mathrm{Kg})$ with a precision of $100 \mathrm{~g}\left(\mathrm{SECA}^{\mathrm{TM}}\right)$. The mean value of three measures was considered the average weight of the children. The height was obtained with a stadiometer (Alturexata ${ }^{\circledR}$ ) with a scale inside.

The height-for-age, weight-for-age, and body mass index-for-age indexes were used to classify their nutritional status, which was based on the $\mathrm{Z}$ scores following the World Health Organization (WHO) growth reference curves [5] [6].

\subsection{Sample Size}

The sample size was calculated by assuming an odds ratio of 0.2 for sleeping under ITNs, control exposure of 50\%, and case to control the ratio of 1:1 for a total sample size of 120 . The sample size was 130 . However, only 119 children and adolescents were included in the study.

\subsection{Data Analysis}

Data are presented as frequencies of occurrence or as median and ranges. Both bivariate and multivariable logistic regression was performed to identify factors associated with malaria. Data were analyzed using Statistical Package for the Social Sciences (SPSS) software, Release 21 (IBM Inc., Armonk, NY, USA). The accepted significance level was $5 \%$. 


\subsection{Ethics Approval and Consent to Participate}

This study was revised and approved by the Ethical Committee of The Health Science Institute of UFPA, Number 261.593/2013. The written informed consent was obtained from each guardian of children and adolescents.

\section{Results}

A total of 119 children and adolescents were included in the study, amongst them, 58 (48.7\%) cases and 61 (51.3\%) controls. The mean age of each group was 7.3 (4.5) years and 7.6 (4.2), respectively. Most of the study participants from both groups were male. The social and economic data of the case groups showed that most of the parents or legal tutors have an unstable occupation with a family income below 100 US, indicating a low socio-economic status. The educational degree, occupation, and family income were significant predictors for malaria (Table 1).

The long-lasting insecticidal nets (LLIN) was the most used prophylactic measure in both groups of the study. There was no report of chemoprophylaxis in both groups. Moreover, a small proportion of houses in both groups reported the use of windows networks and indoor residual spraying (IRS). A similar result was found with the individual use of repellents in both groups. These outcomes do not modify the occurrence of malaria.

The knowledge of the transmission of malaria was different between the groups and was a significant factor for malaria infection. Finally, the presence of peridomiciliary breeding sites for Anopheles vector was different between groups and considered the most important predictor of the disease (Table 2).

\section{Discussion}

The knowledge and management of factors associated with the transmission of malaria in the Brazilian Amazon basin are essential to guide the surveillance efforts to reducing the social and economic negative impact of the disease. The strategies of the Brazilian Health Authorities to reduce the burden of the disease are based on the control of Anopheles vector and in the early diagnosis and prompt treatment of cases [7]. However, geographical diversity and the extent of the Amazon basin constitute a challenge to the fight against malaria. In the Marajo Island, there are areas with intense touristic activities in the north of the island coexisting with those where the agricultural and fisher practices predominate. A substantial difference in biomes across regions is noted with most of the cases of the disease occurs in municipalities from the center to the south of the island [2].

Most of children and adolescents with $P$. vivax were from families that live in poverty receiving a monthly income below 100 US\$, which is in line with data from the WHO that demonstrated that the disease concentrates in areas with low economic status in the tropical regions, where individuals present difficulty to access public health services for diagnosis and treatment of the disease as well 
Table 1. Socio demographic characteristics of the study participants.

\begin{tabular}{|c|c|c|c|c|c|}
\hline \multirow{2}{*}{ Characteristic } & \multicolumn{2}{|c|}{ Case $(n=58)$} & \multicolumn{2}{|c|}{ Control $(n=61)$} & \multirow{2}{*}{$P$ value } \\
\hline & $\mathbf{n}$ & $\%$ & $\mathbf{n}$ & $\%$ & \\
\hline \multicolumn{6}{|l|}{ Sex } \\
\hline Male & 38 & 65.5 & 36 & 59.0 & \multirow{2}{*}{$0.5879^{*}$} \\
\hline Female & 20 & 34.5 & 25 & 41.0 & \\
\hline \multicolumn{6}{|l|}{ Age range, years } \\
\hline 2 to 4 & 25 & 43.1 & 21 & 34.4 & \multirow{3}{*}{$0.3575^{\star *}$} \\
\hline 5 to 9 & 14 & 24.1 & 22 & 36.1 & \\
\hline 10 to 15 & 19 & 32.8 & 18 & 29.5 & \\
\hline \multicolumn{6}{|l|}{ Nutritional status (A/I) } \\
\hline Low & 14 & 25.0 & 8 & 17.5 & \multirow[t]{2}{*}{$0.1895^{*}$} \\
\hline Appropriate & 44 & 75.0 & 53 & 82.5 & \\
\hline \multicolumn{6}{|l|}{ Guardian } \\
\hline Mother & 52 & 89.7 & 53 & 86.9 & \multirow[t]{2}{*}{$0.8539^{*}$} \\
\hline Other & 6 & 10.3 & 8 & 13.1 & \\
\hline \multicolumn{6}{|l|}{ Educational status } \\
\hline No formal education & 39 & 67.2 & 19 & 31.1 & \multirow[t]{3}{*}{$<0.0001^{\star \star}$} \\
\hline Primary (1 - 8 th) & 15 & 25.9 & 17 & 27.9 & \\
\hline Secundary+ & 4 & 6.9 & 11 & 18.0 & \\
\hline \multicolumn{6}{|l|}{ Marital status } \\
\hline Married & 36 & 62.1 & 42 & 68.8 & \multirow[t]{2}{*}{$0.5583^{*}$} \\
\hline Single & 22 & 37.9 & 19 & 31.2 & \\
\hline \multicolumn{6}{|l|}{ Occupation } \\
\hline Unstable & 53 & 91.4 & 40 & 65.6 & \multirow[t]{2}{*}{$0.0046^{\star}$} \\
\hline Stable & 5 & 8.6 & 21 & 34.4 & \\
\hline \multicolumn{6}{|l|}{ Family income } \\
\hline$<100$ US\$ & 42 & 72.4 & 31 & 50.8 & \multirow[t]{2}{*}{$0.0258^{*}$} \\
\hline$\geq 100$ US\$ & 16 & 27.6 & 30 & 49.2 & \\
\hline
\end{tabular}

${ }^{\star}$ Chi-square test. ${ }^{* *} \mathrm{G}$ test.

as to the prophylactic measures [1]. The disease impairs the economic development of endemic areas as most of the individuals affected are in productive age, which contributes to maintaining the cycle of poverty-related to malaria [7] [8].

Poverty also contributes to the low educational degree, as most of the inhabitants of the study area change in early ages from educational activities to unstable occupational activities in order to support their families. There is a significant influence of socio-economical and educational status on the risk of malaria [9]. In the study, the low educational degree, the family income, and the unstable occupation were significant factors for malaria vivax.

Poverty and the low educational degree accompanied the unsatisfactory familiarity with the knowledge of the disease in the cases. A previous study showed that the unsatisfactory knowledge of the disease contributed to increasing the 
Table 2. Factors associated with malaria infection in children.

\begin{tabular}{|c|c|c|c|c|}
\hline Factors & Case & Control & $\operatorname{COR}(95 \% \mathrm{CI})$ & AOR (95\% CI) \\
\hline \multicolumn{5}{|l|}{ Sex } \\
\hline Male & 38 & 36 & $1.32(0.63-3.78)$ & $1.53(0.67-3.46)$ \\
\hline Female & 20 & 25 & & \\
\hline \multicolumn{5}{|l|}{ Age range, years } \\
\hline 2 to 9 & 39 & 43 & $0.86(0.40-1.87)$ & $0.89(0.37-2.12)$ \\
\hline 10 to 16 & 19 & 18 & & \\
\hline \multicolumn{5}{|l|}{ Educational status } \\
\hline Primary (1 - 8 th) & 54 & 36 & $9.38(3.01-29.2)$ & $6.11(1.87-19.9)^{*}$ \\
\hline Secundary+ & 4 & 25 & & \\
\hline \multicolumn{5}{|l|}{ Nutritional status } \\
\hline Inadequate & 14 & 8 & $2.11(0.81-5.48)$ & $2.02(0.71-5.76)$ \\
\hline Adequate & 44 & 53 & & \\
\hline \multicolumn{5}{|c|}{ Knowledge on malaria } \\
\hline No & 21 & 11 & $2.58(1.11-6.0)$ & $2.74(1.04-7.24)^{\star}$ \\
\hline Yes & 37 & 50 & & \\
\hline \multicolumn{5}{|l|}{ LLIN } \\
\hline Yes & 48 & 53 & $1.38(0.50-3.78)$ & $2.90(0.72-11.71)$ \\
\hline No & 10 & 8 & & \\
\hline \multicolumn{5}{|l|}{ SRI } \\
\hline Yes & 6 & 9 & $1.50(0.50-4.52)$ & $2.18(0.59-8.02)$ \\
\hline No & 52 & 52 & & \\
\hline \multicolumn{5}{|l|}{ Repellent } \\
\hline Yes & 8 & 13 & $1.69(0.64-4.45)$ & $0.53(0.17-1.69)$ \\
\hline No & 50 & 48 & & \\
\hline \multicolumn{5}{|c|}{ Mosquito breeding sites } \\
\hline Yes & 2 & 25 & $19.44(4.34-87.1)$ & $22.48(4.65-108.9)^{\star}$ \\
\hline No & 56 & 36 & & \\
\hline
\end{tabular}

${ }^{*} \mathrm{p}<0.05$ in multivariable analysis. COR: crude odds ratio. AOR-adjusted odds ratio.

risk of infection [10].

There is a synergism between infection and nutrition, and children and adolescents with low nutritional status have a high probability of worsening the signs and symptoms of the disease. The deaths related to malaria in children and adolescents have been associated with undernutrition and deficiency of nutrients like vitamin A, zinc, folate, and iron, which are essential elements for the defense of the human host. However, there was no significant association between the nutritional status and the occurrence of the disease, which could be due to the high proportion of eutrophic individuals in the study groups [11] [12] [13] [14].

The use of LLIN is the principal prophylactic measure against Anopheles bite 
adopted by the Brazilian Health Authorities, and the data showed a high coverage of LLIN in both study groups. Other prophylactic measures as IRS, the use of repellents, and the windows network were reported by a small proportion of individuals in the study, which could be related to the social vulnerability of the inhabitants of Anajas.

The presence of breeding sites for Anopheles mosquito in the peridomicile was the most critical factor for malaria infection. These sites result from the inappropriate discharge of domestic residues, which creates a small collection of water that suffers the action of the tide in the rainy season, being dissipated by the Anajas River. However, in the dry season, these small collections of water constitute a suitable site for the breeding of the Anopheles vectors. Thus, the cases of malaria decrease in the rainy season and begin to increase in the transition of rainy to dry seasons [15].

The limitation of the study was the reduced number of participants due to the difficulties of including individuals in the control group. However, there was a similar distribution of participants between the study groups.

\section{Conclusion}

Malaria occurs in children and adolescents of both genders. The low social and economic status of their families are significant predictors of the disease. These factors impact the educational degree of the guardians leading to the unfamiliarity with the disease. Finally, the presence of breeding sites for Anopheles mosquito surrounding individual domiciles is a significant factor for the disease.

\section{Conflicts of Interest}

The authors declare no conflicts of interest regarding the publication of this paper.

\section{References}

[1] World Health Organization (WHO) Malaria. Factsheet. Atualizado em 27 de março de 2019. https://www.who.int/news-room/fact-sheets/detail/malaria

[2] BRASIL. Ministério da Saúde. Secretaria de Vigilância em Saúde. Lista de municípios pertencentes às áreas de risco ou endêmicas para malária.

http://portalarquivos2.saude.gov.br/images/pdf/2019/junho/25/Lista-de-municipios -pertencentes-as-areas-de-risco-ou-endemicas-para-malaria.pdf

[3] Defi, G.B., Belachew, A., Addissie, A. and Hailemariam, Z. (2015) A Malaria Outbreak in Ameya Woreda, South-West Shoa, Oromia, Ethiopia, 2012: Weaknesses in Disease Control, Important Risk Factors. American Journal of Health Research, 3, 125-129. https://doi.org/10.11648/j.ajhr.20150303.12

[4] Mugwagwa, N., Mberikunashe, J., Gombe, N.T., Tshimanga, M. and Bangure, D., Mungati, M. (2015) Factors Associated with Malaria Infection in Honde Valley, Mutasa District, Zimbabwe. BMC Research Notes, 8, Article No. 829.

https://doi.org/10.1186/s13104-015-1831-3

[5] World Health Organization (WHO) WHO Reference 2007: Growth Reference 5-19 Years. http://www.who.int/growthref/en/ 
[6] Brasil (2020) Ministério da Saúde. Sistema de Vigilância Alimentar e Nutricional. http://sisaps.saude.gov.br/sisvan/relatoriopublico/index

[7] BRASIL (2010) Ministério da Saúde. Secretaria de Vigilância em Saúde. Departamento de Vigilância Epidemiológica. Guia prático de tratamento da malária no Brasil. MS, Brasília, 36 p. (Serie A. Normas e Manuais Técnicos)

[8] Junior, S.G.L, Pamplona, V.M.S., Corvelo, T.C.O. and Ramos, E.M.L.S. (2014) Quality of Life and the Risk of Contracting Malaria by Multivariate Analysis in the Brazilian Amazon Region. Malaria Journal, 13, Article No. 86. https://doi.org/10.1186/1475-2875-13-86

[9] Maciel, F.O., Lima e Silva, R.B. and Souto, R.N.P. (2011) Fatores de riscos associados à transmissão de malária humana, em áreas de ressacas, nos bairros Novo Horizonte e Zerão, Macapá, Amapá, Brasil. Biota Amazônia, 1, 49-57.

https://doi.org/10.18561/2179-5746/biotaamazonia.v1n1p49-57

[10] Ferreira, I.M., Yokoo, E.M., Souza-Santos, R., Galvão, N.D. and Atanaka-Santos, M. (2012) Factors Associated with the Incidence of Malaria in Settlement Areas in the District of Juruena, Mato Grosso State, Brazil. Ciência \& Saúde Coletiva, 17, 24152424. https://doi.org/10.1590/S1413-81232012000900022

[11] Ambrus-SR, J.L. and Ambrus-JR, J.L. (2004) Nutrition and Infectious Diseases in Developing Countries and Problems of Acquired Immunodeficiency Syndrome. Experimental Biology and Medicine, 229, 464-472. https://doi.org/10.1177/153537020422900603

[12] Caulfield, L.E., Richard, S.A. and Black, R.E. (2004) Undernutrition as an Underlying Cause of Malaria Morbidity and Mortality in Children Less than Five Years Old. American Journal of Tropical Medicine and Hygiene, 71, 55-63. https://doi.org/10.4269/ajtmh.2004.71.55

[13] Crookston, B.T., Alder, S.C., Boakie, I., Merrill, R.M., Amuasi, J.H., Porucznik, C.A., et al. (2010) Exploring the Relationship between Chronic Undernutrition and Asymptomatic Malaria in Ghanaian Children. Malaria Journal, 9, Article No. 39. https://doi.org/10.1186/1475-2875-9-39

[14] Hall, A., Zhang, Y., Macarthur, C. and Baker, S. (2012) The Role of Nutrition in Integrated Programs to Control Neglected Tropical Diseases. BMC Medicine, 10, Article No. 41. https://doi.org/10.1186/1741-7015-10-41

[15] Tesfahunegn, A., Berhe, G. and Gebregziabher, E. (2019) Risk Factors Associated with Malaria Outbreak in Laelay Adyabo District Northern Ethiopia, 2017: Case-Control Study Design. BMC Public Health, 19, Article No. 484.

https://doi.org/10.1186/s12889-019-6798-x 